IEA/SHC

Task 57, Subtask B

Draft proposals for new test procedures

B4: Final Draft

\title{
Draft proposals for Test methods for close-coupled solar water heating systems - Reliability and safety
}

HE Zinian

Beijing Solar Energy Research Institute, China 28 September 2018 


\section{Contents}

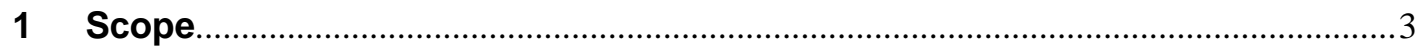

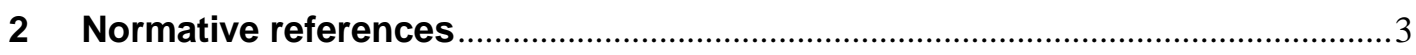

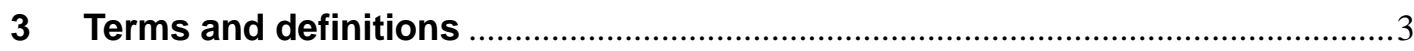

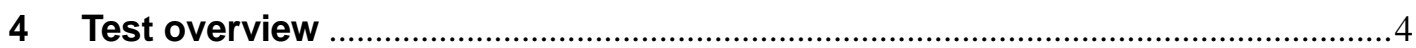

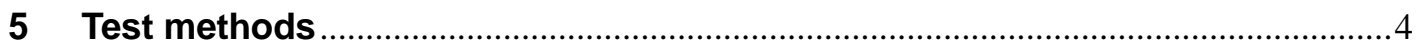

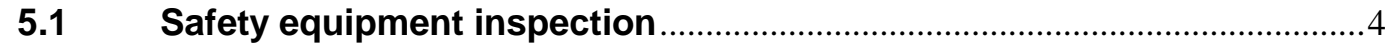

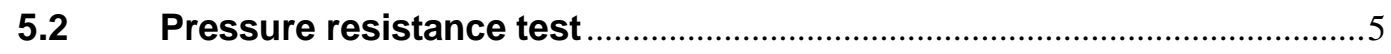

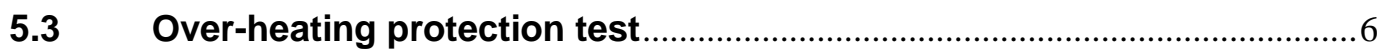

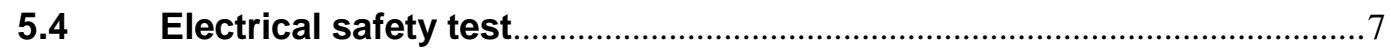

5.5 Exposure test ................................................................................. 8

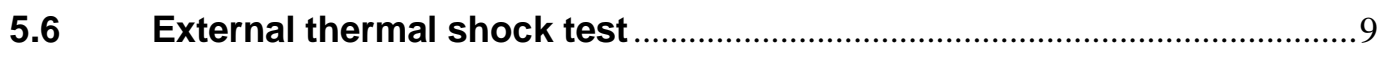

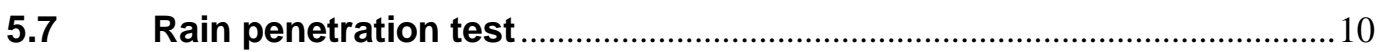

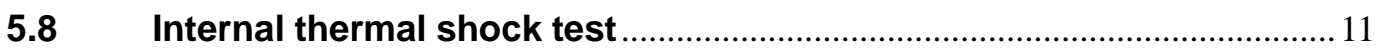

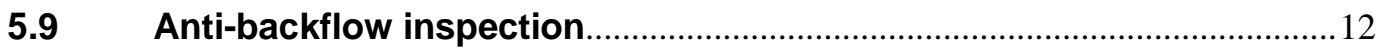

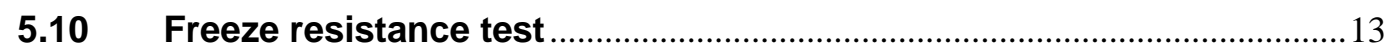

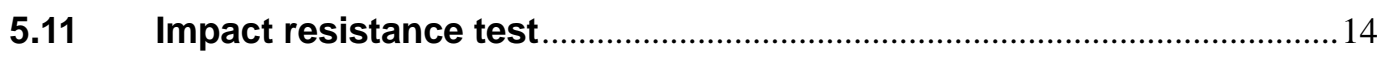

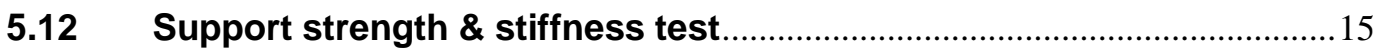

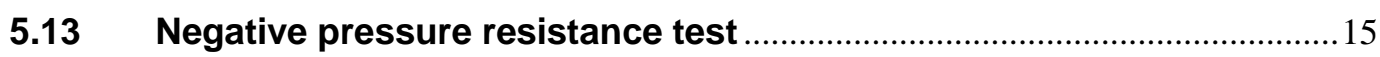

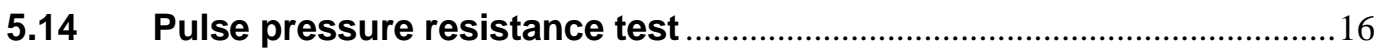

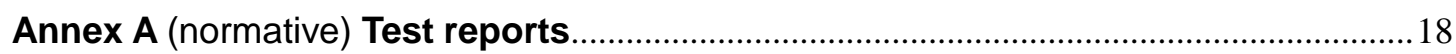

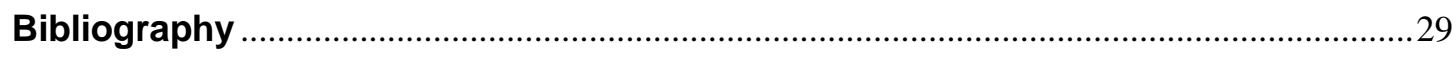




\section{Test methods for close-coupled solar water heating systems - Reliability and safety}

\section{Scope}

This standard specifies test methods for assessing the reliability and safety with regard to close-coupled solar water heating systems.

This standard is applicable to all types of close-coupled solar water heating systems, including those using flat-plate collectors with thermo-siphon circulation; and those using evacuated tubes directly connected to the storage tank.

This standard is also applicable to close-coupled solar water heating systems assisted by air-source heat-pumps; and to close-coupled solar water heating systems with auxiliary electric energy for normal system operation.

\section{Normative references}

The following documents, in whole or in part, are normatively referenced in this document and are indispensable for its application. For dated references, only the edition cited applies. For undated references, the latest edition of the referenced document (including any amendments) applies.

ISO 9459 Solar heating-Domestic water heating systems

ISO 9488 Solar energy - Vocabulary

ISO 9806 Solar energy - Solar thermal collectors - Test methods

ISO 22975 -1 Solar energy - Collector components and materials - Part 1: Evacuated tubes - Durability and performance

EN 12976 - 2 Thermal solar systems and components - Factory made systems Part 2: Test methods;

\section{Terms and definitions}

For the purpose of this standard, the terms and definitions given in ISO 9488 apply, together with the following additional terms and definitions:

\section{1 close-coupled system}

system in which the storage device is mounted directly adjacent to the collector

\section{2 pressure resistance}

storage tank and pipelines, which water in the storage tank may directly enter, have the capability to withstand a certain pressure 


\section{3 negative pressure resistance}

system with a sealed storage tank has the capability to withstand a certain negative pressure caused by discharging hot water

\section{4 pulse pressure resistance}

system with a sealed storage tank has the capability to withstand multiple pulse pressure caused by long-term alternately charging cold water and discharging hot water

\section{Test overview}

Reliability and safety tests for close-coupled solar water heating systems are specified in Clause 5. The tests shall be performed in the sequence according to Table 1.

Table 1 - Test list

\begin{tabular}{|c|c|}
\hline Clause & Test \\
\hline 5.1 & Safety equipment inspection \\
\hline 5.2 & Pressure resistance test \\
\hline 5.3 & Over-heating protection test \\
\hline 5.4 & Electrical safety test ${ }^{a}$ \\
\hline 5.5 & Exposure test \\
\hline 5.6 & External thermal shock test \\
\hline 5.7 & Rain penetration test \\
\hline 5.8 & Internal thermal shock test \\
\hline 5.9 & Anti-backflow inspection ${ }^{b}$ \\
\hline 5.10 & Freeze resistance test ${ }^{c}$ \\
\hline 5.11 & Impact resistance test \\
\hline 5.12 & Support strength \& stiffness test \\
\hline 5.13 & Negative pressure resistance test ${ }^{d}$ \\
\hline 5.14 & Pulse pressure resistance test ${ }^{\mathrm{e}}$ \\
\hline \multicolumn{2}{|c|}{$\begin{array}{l}\text { a. Electrical safety test shall be performed only for systems with electric equipment. } \\
\text { b. Anti-backflow inspection shall be performed only for thermo-siphon systems. } \\
\text { c. Freeze resistance test shall be performed only for systems claimed to be freeze resistant. } \\
\text { d. Negative pressure resistance test shall be performed only for systems with closed storage tank. } \\
\text { e. Pulse pressure resistance test shall be performed only for systems with closed storage tank. }\end{array}$} \\
\hline
\end{tabular}

\section{Test methods}

\subsection{Safety equipment inspection}

\subsubsection{Objective}

This inspection is intended to assess the capability of a system to withstand the highest working temperature or the highest steam flow-rate, which probably causes danger to human or to the environment.

\subsubsection{Items of inspection}




\subsubsection{Safety relief valves}

Check the system and its documentation to verify that

a) Each circuit in the system, which might be closed, shall be equipped with at least one safety relief valve;

b) The safety relief valve shall withstand the highest working temperature of the heat transfer medium;

c) The safety relief valve shall be dimensioned so that it can release the highest hot water flow-rate or the highest steam flow-rate which probably occurs.

d) The safety relief valve shall be suitably arranged so that the steam or the heat transfer medium released must not cause any danger to human or to the environment.

\subsubsection{Connecting pipes between the safety relief valve and the expansion vessel}

If the system is equipped with connecting pipes between the safety relief valve and the expansion vessel, check the system and its documentation to verify that

a) Connecting pipes between the safety relief valve and the expansion vessel cannot be closed;

b) Inner diameter of the connecting pipes shall be dimensioned so that the pressure anywhere in the collector loop shall not exceed the maximum allowed pressure under conditions of the highest hot water flow-rate or the highest steam flow-rate which probably occurs;

c) The safety relief valve and the expansion vessel are connected and laid in such a way that any accumulation of dirt, scale or similar impurities can be avoided.

\subsubsection{Emptying pipelines}

If the system is equipped with emptying pipelines, check the system and its documentation to verify that the emptying pipelines are laid in such a way that they cannot freeze and cannot accumulate water inside.

\subsection{Pressure resistance test}

\subsubsection{Objective}

This test is intended to assess the capability of a system to withstand the working pressure without failure.

\subsubsection{Test apparatus}

The pressure resistance test apparatus is shown in Figure 1. 


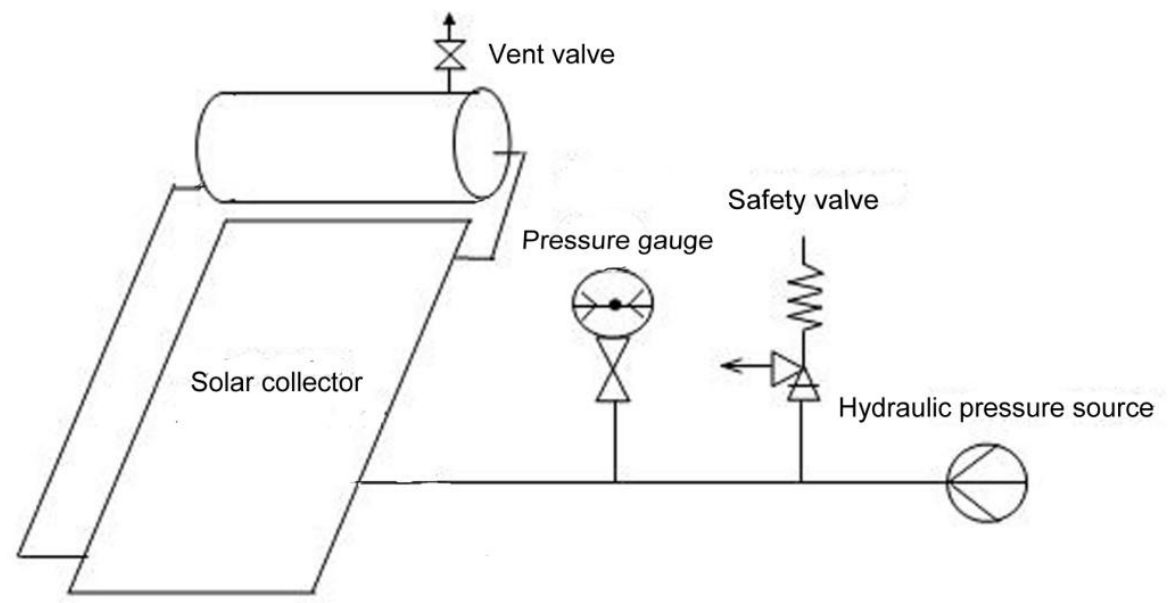

Figure 1 - Schematic for pressure resistance test for the solar system

\subsubsection{Test conditions}

a) Ambient temperature: $0{ }^{\circ} \mathrm{C}-39^{\circ} \mathrm{C}$;

b) Test pressure: For an open system or a vented system, 1.25 times the rated working pressure (the rated working pressure shall not be less than $0.05 \mathrm{MPa}$ ); and for a closed system, 1.5 times the rated working pressure (the rated working pressure shall not be less than $0.6 \mathrm{MPa}$ ).

\subsubsection{Test procedure}

a) The close-coupled solar water heating system shall be filled with water, and drained residual air through the vent valve.

b) The vent valve shall be closed before test, and then the hydraulic pressure system shall be gradually pressurized to the test pressure.

c) The test pressure for the open or the vented storage tank shall be 1.25 times the rated working pressure; the test pressure for the closed storage tank shall be 1.5 times the rated working pressure.

d) The test pressure shall be maintained for $10 \mathrm{~min}$ while the system shall be inspected for swelling, deformation, leakage and rupture.

\subsubsection{Test results}

The close-coupled solar water heating system shall be inspected for leakage; the storage tank, collector, auxiliary heat source and pipelines shall be inspected for swelling, deformation and rupture; the evacuated tubes shall be inspected for longitudinal displacement, deformation and rupture.

The results of these inspections shall be reported together with values of pressure, ambient temperature and duration of the test.

\subsection{Over-heating protection test}

\subsubsection{Objective}


This test is intended to assess the capability of a system to protect from the over-heating without failure.

\subsubsection{Test conditions}

a) Ambient temperature: $0^{\circ} \mathrm{C}-39^{\circ} \mathrm{C}$;

b) Daily solar irradiation: $\mathrm{H} \geq 16 \mathrm{MJ} / \mathrm{m}^{2}$;

c) Test duration: Continuous 2 days.

\subsubsection{Test procedure}

a) The close-coupled solar water heating system shall be installed according to the manufacturer's requirements, and filled with water and maintained at the working pressure.

b) After shutting off the electric power, the system shall be tested at a daily solar irradiation $\geq 16 \mathrm{MJ} / \mathrm{m}^{2}$ for a period of two days.

c) As soon as the collector circuit starts to discharge the steam, the water in the system shall be quickly drained down;

d) The test is finished until the volume of drained water is more than or equal to the capacity of the system.

e) For the system containing an antifreeze fluid, they shall be checked whether sufficient precautions have been taken to prevent the antifreeze fluid from deterioration as a result of high temperature conditions.

f) If non-metallic materials are used in any circuit, the highest temperature in the circuit shall be measured during the over-temperature protection test.

\subsubsection{Test results}

The close-coupled solar water heating system shall be inspected for leakage, and the pipelines shall be inspected for swelling.

The results of these inspections shall be reported together with values of daily solar irradiation and ambient temperature during the test.

\subsection{Electrical safety test}

\subsubsection{Objective}

This test is intended to assess the capability of a system to withstand the electricity, which probably causes danger to human.

\subsubsection{Air-source heat-pump assisted solar water heating system}

Electrical safety test of an air-source heat-pump assisted close-coupled solar water heating system shall be carried out according to the methods specified by the related standards. 


\subsubsection{Solar water heating system with auxiliary electric energy}

Electrical safety test of a close-coupled solar water heating system with auxiliary electric energy shall be carried out according to the methods specified by the related standards.

\subsection{Exposure test}

\subsubsection{Objective}

This test is intended to assess the capability of a system to withstand the exposure condition without failure.

\subsubsection{Test apparatus}

The exposure test apparatus is shown in Figure 2.
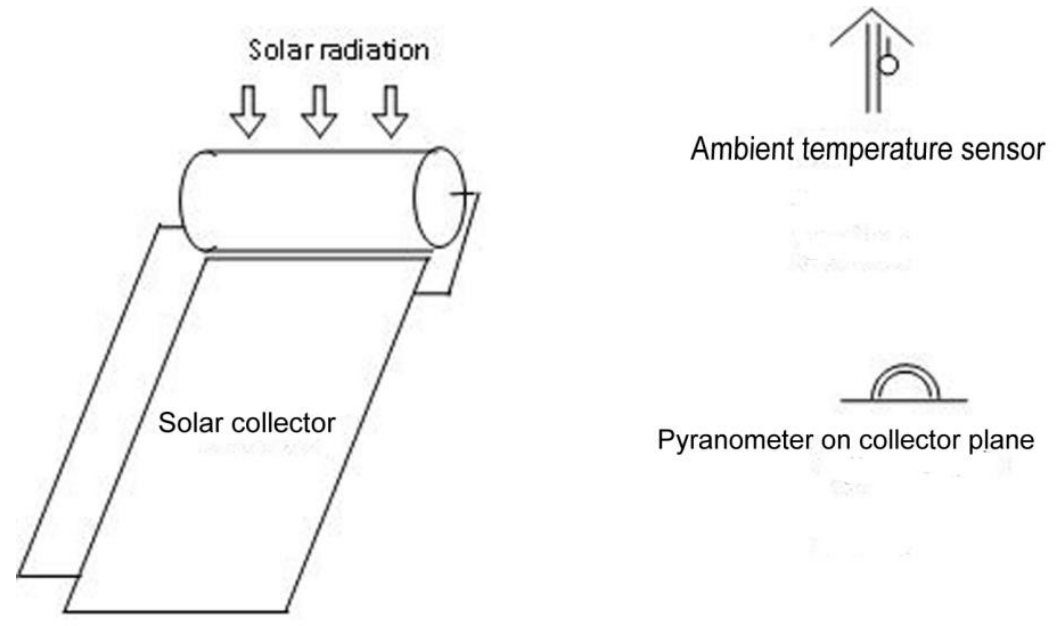

Figure 2 - Schematic for exposure test for the solar system

\subsubsection{Test conditions}
a) Ambient temperature: $0^{\circ} \mathrm{C}-39^{\circ} \mathrm{C}$;
b) Daily solar irradiation: $H \geq 16 \mathrm{MJ} / \mathrm{m}^{2}$;
c) Test duration: Continuous 2 days.

\subsubsection{Test procedure}

a) The close-coupled solar water heating system shall be mounted outdoors, but is not filled with fluid.

b) All the inlets and outlets of the fluid pipelines are blocked to prevent cooling by natural circulation of air except one outlet, which is kept open to permit free expansion of air in the absorber.

c) Solar irradiation and ambient temperature values shall be hourly recorded. The collector is exposed until the test conditions are satisfied.

d) At the end of the exposure test, a visual inspection shall be made for signs of damage.

\subsubsection{Test results}


The close-coupled solar water heating system shall be inspected for crack or deformation.

The results of these inspections shall be reported together with values of daily solar irradiation and ambient temperature during the test.

\subsection{External thermal shock test}

\subsubsection{Objective}

This test is intended to assess the capability of a system to withstand the external thermal shock without failure.

\subsubsection{Test apparatus}

The external thermal shock test apparatus is shown in Figure 3.
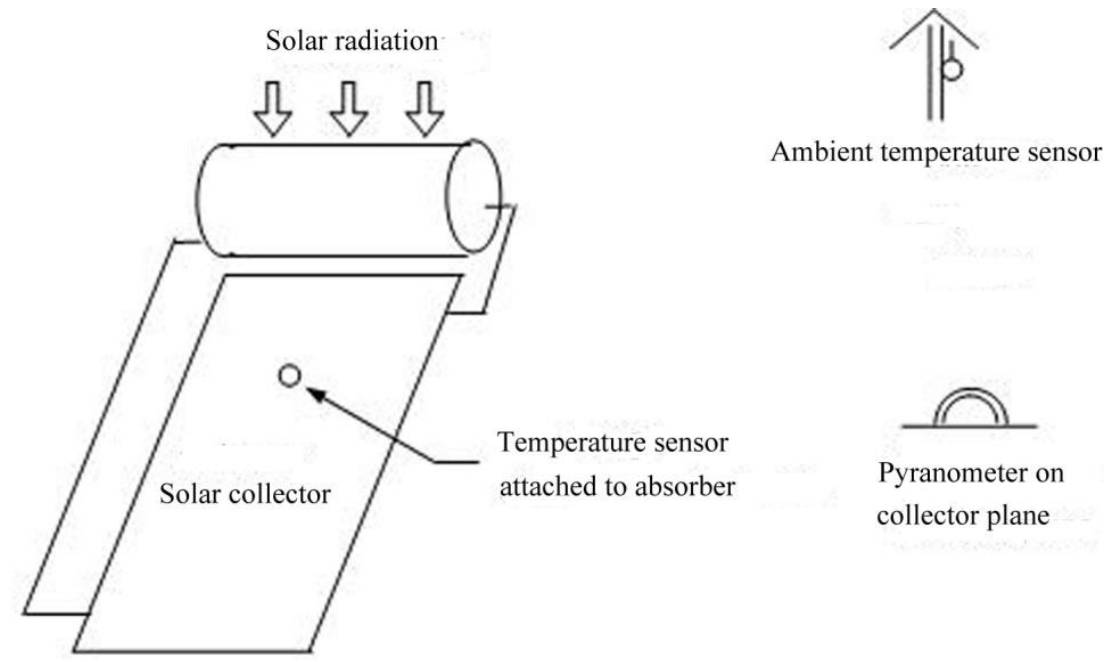

Figure 3 - Schematic for external thermal shock test for the solar system

\subsubsection{Test conditions}

a) Ambient temperature: $0^{\circ} \mathrm{C}-39^{\circ} \mathrm{C}$;

b) Solar irradiance: $\mathrm{G} \geq 600 \mathrm{~W} / \mathrm{m}^{2}$;

c) Spray water temperature: $<25^{\circ} \mathrm{C}$;

d) Spray water flow-rate: $180 \mathrm{~L} / \mathrm{h} \cdot \mathrm{m}^{2}-216 \mathrm{~L} / \mathrm{h} \cdot \mathrm{m}^{2}$.

\subsubsection{Test procedure}

a) The close-coupled solar water heating system shall be mounted outdoors, but is not filled with water.

b) All the inlets and outlets of fluid pipes shall be blocked to prevent cooling through natural circulation of air, except one which shall be left open to permit free expansion of air in the absorber.

c) A temperature sensor is attached to the absorber to monitor its temperature during the test. The sensor shall be positioned at $2 / 3$ of the absorber height and $1 / 2$ of the 
absorber width. It shall be fixed firmly in a position to ensure good thermal contact with the absorber. The sensor shall be shielded from solar radiation.

d) A water spray nozzle shall be arranged to provide a uniform spray of water over the system.

e) The system shall be maintained in quasi-steady state conditions under a proper high level of solar irradiance $\left(\geq 600 \mathrm{~W} / \mathrm{m}^{2}\right)$ for a period of $1.5 \mathrm{~h}$ before the water spray is turned on, and values of solar irradiance and ambient temperature shall be recorded every 5 min.

f) The system shall be then cooled by the water spray for 15 min before being inspected.

g) Twice external thermal shock tests shall be carried out for the close-coupled solar water heating system.

h) The external thermal shock test could be combined with the exposure test at the same time. The first external thermal shock shall be carried out during the first $10 \mathrm{~h}$, and the second external thermal shock shall be carried out during the last $10 \mathrm{~h}$.

\subsubsection{Test results}

The system shall be inspected for any cracking, deformation, condensation or water penetration.

The results of the inspection shall be reported together with measured values of solar irradiance and ambient temperature during the test, as well as values of spray water temperature and spray water flow-rate.

\subsection{Rain penetration test}

\subsubsection{Objective}

This test is intended to assess the capability of a system to prevent from the rain penetration without failure.

\subsubsection{Test apparatus}

The rain penetration test apparatus is shown in Figure 4.

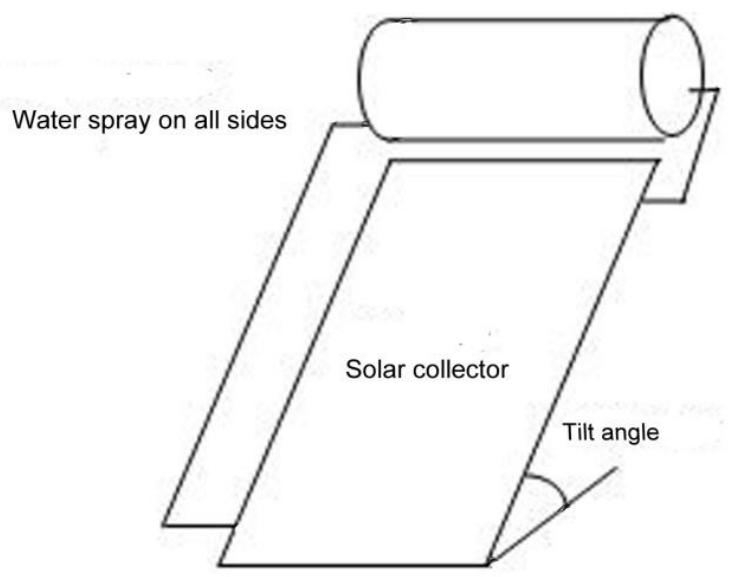

Figure 4 - Schematic for rain penetration test for the solar system 


\subsubsection{Test conditions}
a) Ambient temperature: $0^{\circ} \mathrm{C}-39^{\circ} \mathrm{C}$;
b) Spray water temperature: $<25^{\circ} \mathrm{C}$;
C) Spray water flow-rate: $180 \mathrm{~L} / \mathrm{h} \cdot \mathrm{m}^{2}-216 \mathrm{~L} / \mathrm{h} \cdot \mathrm{m}^{2}$.

\subsubsection{Test procedure}

a) The close-coupled solar water heating system shall have its inlets and outlets pipes blocked.

b) The system shall be placed in a test rig at the smallest tilt angle to the horizontal recommended by the manufacturer.

c) If this tilt angle is not specified, the collector shall be placed at a tilt angle of $45^{\circ}$ or less to the horizontal.

d) The system shall be then sprayed on all sides using water spray nozzles for a test period of $1 \mathrm{~h}$.

e) Values of sprayed water temperature and spray water flow-rate shall be recorded every 5 min.

\subsubsection{Test results}

A visual inspection shall be performed on the existence of water penetration inside the collectors.

The results of the inspection shall be reported together with measured values of ambient temperature, spray water temperature and spray water flow-rate.

\subsection{Internal thermal shock test}

\subsubsection{Objective}

This test is intended to assess the capability of a system to withstand the internal thermal shock without failure.

\subsubsection{Test apparatus}

The internal thermal shock test apparatus is shown in Figure 5. 


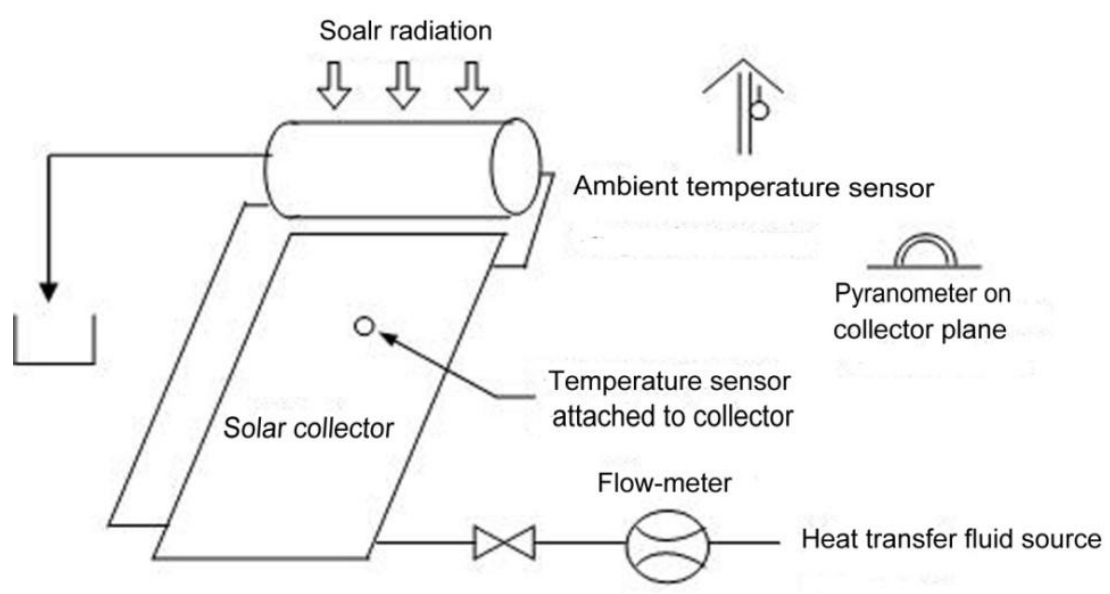

Figure 5 - Schematic for internal thermal shock test for the solar system

\subsubsection{Test conditions}

a) Ambient temperature: $0^{\circ} \mathrm{C}-39^{\circ} \mathrm{C}$;

b) Cooling water/heat transfer fluid temperature: $<25^{\circ} \mathrm{C}$;

c) Cooling water/heat transfer fluid flow-rate: $\geq 72 \mathrm{~L} / \mathrm{h} \cdot \mathrm{m}^{2}$.

\subsubsection{Test procedure}

a) The close-coupled solar water heating system shall be mounted outdoors, but shall not be filled with water/heat transfer fluid.

b) One of its fluid pipes is connected via a valve to the heat transfer fluid source and the other is left open initially to permit the free expansion of air in the absorber and also to permit the heat transfer fluid to leave the absorber (and to be collected).

c) A temperature sensor is attached to the absorber to monitor its temperature during the test. The sensor shall be positioned at $2 / 3$ of the absorber height and $1 / 2$ of the absorber width. It shall be fixed firmly in a position to ensure good thermal contact with the absorber. The sensor shall be shielded from solar radiation.

d) The collector shall be maintained under a proper high level of solar irradiance $(\geq$ $600 \mathrm{~W} / \mathrm{m}^{2}$ ) in quasi-steady state conditions for a period of $1.5 \mathrm{~h}$ before it is cooled by filling water/heat transfer fluid for at least $5 \mathrm{~min}$.

e) The system shall be then inspected, and values of solar irradiance and ambient temperature shall be recorded every $5 \mathrm{~min}$.

\subsubsection{Test results}

The system shall be inspected for any cracking, deformation or damage.

The results of the inspection shall be reported together with the measured values of solar irradiance, ambient temperature, absorber temperature, cooling water/heat transfer fluid temperature and flow-rate.

\subsection{Anti-backflow inspection}




\subsubsection{Objective}

This test is intended to assess the capability of a thermo-siphon system to prevent from the backflow when there is no solar irradiation.

\subsubsection{Inspection item}

For a close-coupled solar water heating system with thermo-siphon circulation, visual inspection shall be performed to determine whether the lowest position of the storage tank is above the collector.

\subsection{Freeze resistance test}

\subsubsection{Objective}

This test is intended to assess the capability of a system, which is claimed to be freeze resistant, can withstand freezing without failure.

\subsubsection{Test apparatus}

The freeze resistance test apparatus is shown in Figure 6.

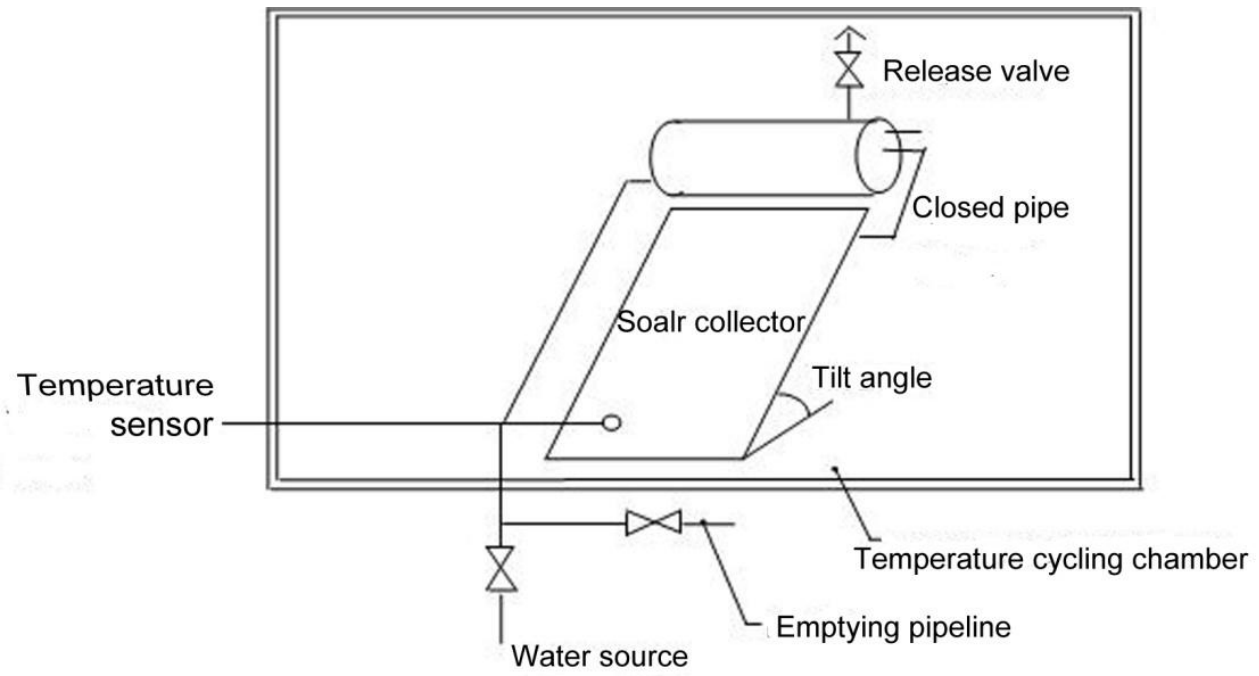

Figure 6 - Schematic for freeze resistance test apparatus for the solar system

\subsubsection{Test conditions}

a) Freeze chamber temperature during the freezing stage: $(-20 \pm 2){ }^{\circ} \mathrm{C}$;

b) Freeze chamber temperature during the thawing stage: Higher than the ambient temperature of $10^{\circ} \mathrm{C}$ or more;

C) Initial water temperature in the storage tank: $(45 \pm 1){ }^{\circ} \mathrm{C}$ or $(10 \pm 1){ }^{\circ} \mathrm{C}$.

\subsubsection{Test procedure}

\subsubsection{Water used as heat transfer fluid}

a) The close-coupled solar water heating system shall be mounted in a freeze chamber. Temperature of the freeze chamber shall be variably cycled. 
b) The collector shall be placed at the smallest angle to the horizontal recommended by the manufacturer. If this tilt angle is not specified, the collector shall be placed at a tilt angle of $30^{\circ}$ to the horizontal.

c) The storage tank shall be filled with water at an initial temperature.

d) The system shall be maintained in the freeze chamber for at least $8 \mathrm{~h}$ during the freezing stage of the cycle.

e) Then the freeze chamber shall be raised to higher than the ambient temperature of $10^{\circ} \mathrm{C}$ or more for $2 \mathrm{~h}$ during the thawing stage of the cycle.

f) The temperature in the storage tank shall be measured close to the inlet.

\subsubsection{Anti-freezing fluid used as heat transfer fluid}

a) The test procedure shall be the same as specified in 5.10.4.1.

b) In addition, freezing point of the anti-freezing fluid shall be measured using a freezing instrument with an accuracy of $\pm 1^{\circ} \mathrm{C}$, and shall be recorded.

\subsubsection{Test results}

a) The system shall be immediately inspected for the existence of freezing with the release valve and the overflow pipe, as well as immediately inspected for the lowest temperature reached inside the collector and the existence of freezing with the heat transfer fluid.

b) Then the system shall be inspected for leakage, breakage, deformation and damage after a period of $2 \mathrm{~h}$ at higher than the ambient temperature of $10^{\circ} \mathrm{C}$ or more.

c) Meanwhile, the system shall be reported for the temperature reached and its tilt angle.

d) The measured freezing point value of the anti-freezing fluid shall be reported and compared with the lowest working temperature specified by the manufacturer, to verify whether the freezing point of the anti-freezing fluid can meet the requirements.

\subsection{Impact resistance test}

\subsubsection{Objective}

This test is intended to assess the capability of a system to withstand the effects of impact caused by hailstones without failure.

\subsubsection{The system using flat-plate collectors with thermo-siphon circulation}

For the close-coupled solar water heating systems using flat-plate collectors with thermo-siphon circulation, flat-plate collectors shall be tested for the impact resistance in accordance with ISO 9806.

\subsubsection{The system using evacuated tubes directly connected to the storage tank}

For the close-coupled solar water heating system using evacuated tubes directly connected to the storage tank, evacuated tubes shall be tested for the impact resistance 
in accordance with ISO $22975-1$.

\subsection{Support strength \& stiffness test}

\subsubsection{Objective}

This test is intended to assess the capability of a system to withstand the effects of moving or additional outside force without failure.

\subsubsection{Test conditions}

a) Off-ground height of one end when not filled with water: $200 \mathrm{~mm}$;

b) Off-ground duration of one end when not filled with water: $5 \mathrm{~min}$;

c) Testing load when filled with water: additional $30 \%$ of the storage tank capacity;

d) Testing duration when filled with water: $15 \mathrm{~min}$.

\subsubsection{Test procedures}

a) Firstly, the system not filled with water shall be mounted at a tilt angle when the system is actually used.

b) One end of the support shall be lifted $200 \mathrm{~mm}$ from the ground for $5 \mathrm{~min}$.

c) After putting it down, check all the components and their junctions for damage or obvious deformation.

d) Every end of the support shall be tested in the same way.

e) Secondly, the system filled with water shall be mounted at a tilt angle when the system is actually used.

f) A testing load (additional 30\% of the storage tank capacity) shall be applied to the middle of the support for $15 \mathrm{~min}$.

g) After completing the test, check the support for damage or obvious deformation.

\subsubsection{Test results}

The support shall be inspected for any damage or obvious deformation.

The results of the inspection shall be reported together with the off-ground height, off-ground duration, testing load and testing duration.

\subsection{Negative pressure resistance test}

\subsubsection{Objective}

This test is intended to assess the capability of a system with a closed storage tank to withstand the effects of negative pressure caused by discharging hot water without failure.

\subsubsection{Test conditions}

a) Vacuum of test device: $0.033 \mathrm{MPa}$; 
b) Testing duration: $5 \mathrm{~min}$.

\subsubsection{Test procedure}

a) The close-coupled solar water heating system shall be connected to a vacuum test device and confirmed to be closed.

b) Then the system shall be evacuated to vacuum of $0.033 \mathrm{MPa}$ and maintained for 5 $\min$.

c) After test, visual inspection shall be performed on the existence of leakage and obvious deformation for the storage tank, auxiliary heat source, solar collector, pipelines and other components of the system.

\subsubsection{Test results}

The storage tank and other components shall be inspected for any leakage or obvious deformation.

The results of the inspection shall be reported together with the test device vacuum and testing duration.

\subsection{Pulse pressure resistance test}

\subsubsection{Objective}

This test is intended to assess the capability of a system with a closed storage tank to withstand the effects of pulse pressure caused by long-term alternately charging cold water and discharging hot water without failure.

\subsubsection{Test conditions}

a) Pulse pressure: $15 \%$ to $(100 \% \pm 5 \%)$ of the rated pressure;

b) Pulse frequency: 25 times $/ \mathrm{min}$ to 60 times $/ \mathrm{min}$;

c) Pulse cycles: 80,000 times;

d) Duration of maintaining the rated pressure: at least $10 \mathrm{~min}$.

\subsubsection{Test procedure}

a) Firstly, the close-coupled solar water heating system shall be connected to a pressure resistance test device, filled with water, pressurized to $(100 \% \pm 5 \%)$ of the rated pressure, and maintained for $5 \mathrm{~min}$; then, check the system for leakage and other anomalies.

b) Secondly, the close-coupled solar water heating system shall be connected to a pulse pressure resistance test device, and then shall be tested according to the above-specified conditions.

c) When the pulse pressure resistance test device is used, the container shall be filled with water at ambient temperature, and air in the container shall be emptied; then, the container shall be alternately pressurized with the pulse pressure. 
d) During the cycle tests, at the end of every 10,000 times, the pressure shall be maintained at the rated pressure for at least $10 \mathrm{~min}$, and visually check the container for obvious deformation; then continue the next cycle test.

e) After the pulse pressure resistance test, visual inspection shall be performed on the existence of leakage and obvious deformation for the storage tank, auxiliary heat source, solar collector, pipelines and other components of the system.

\subsubsection{Test results}

The storage tank and other components shall be inspected for any leakage or obvious deformation.

The results of the inspection shall be reported together with the pulse pressure, pulse frequency and pulse cycles. 


\section{Annex A}

(normative)

\section{Test reports}

Test reports shall be issued in accordance to the International Standard ISO/IEC 17025.

\section{A.1 General}

System reference No:

Test performed by:

Address:

Date, Telephone, Fax:

\section{A.2 Description of the solar water heating system}

Name of manufacturer:

Name of brand:

Serial No:

Drawing document No:

Year of production:

Configuration scheme of the system:

Photograph of the system:

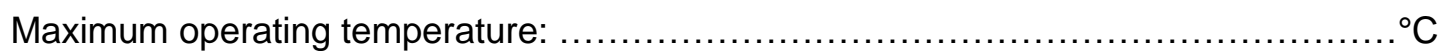

Maximum operating pressure at maximum operating temperature: ...................Pa

Type of system: $\square$ Flat-plate collector with thermo-siphon circulation

$\square$ Evacuated tubes directly connected to storage tank

Flat-plate collector with thermo-siphon circulation:

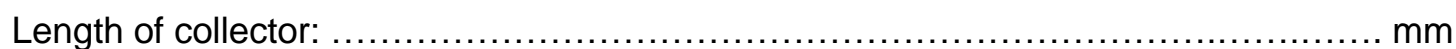

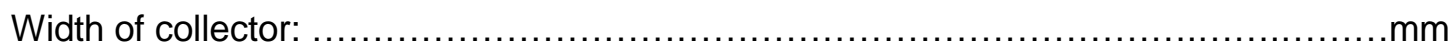

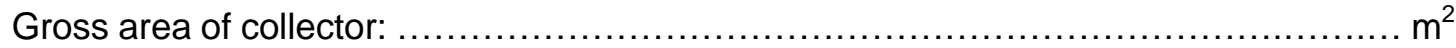

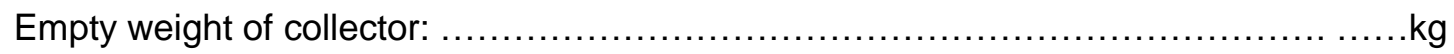

Material of absorber:

Fluid content of collector:

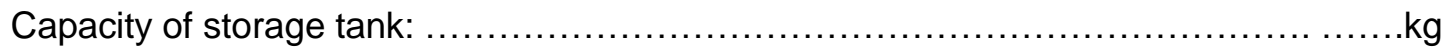

Type of storage tank:

\section{Evacuated tubes directly connected to storage tank:}

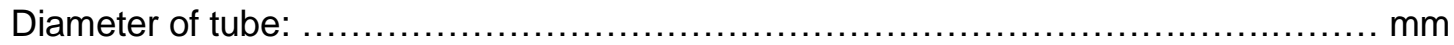

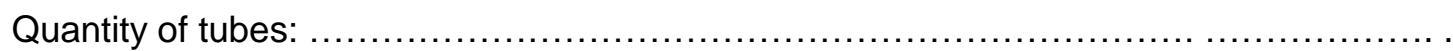

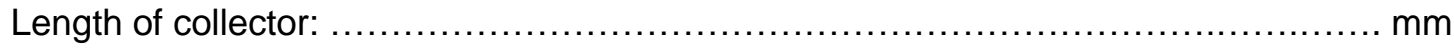

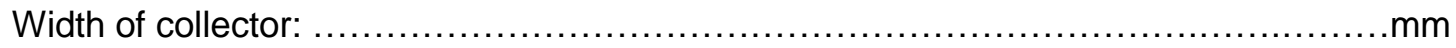

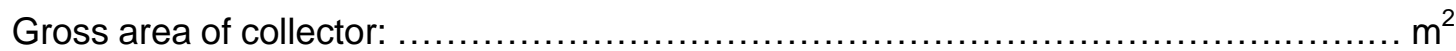

Type of tube:

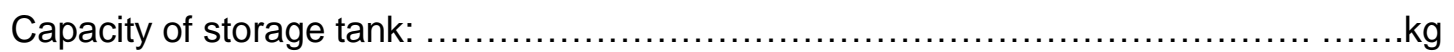




\section{A.3 Summary of main test results for reliability and safety}

All significant damage to the close-coupled solar water heating system should be summarized in Table A.1. Full details should be given in the individual test result sheet.

Table A.1 - Summary of main results for reliability and safety test

\begin{tabular}{|c|c|c|c|c|}
\hline \multirow{2}{*}{ No } & \multirow{2}{*}{ Test } & \multicolumn{2}{|c|}{ Date } & \multirow{2}{*}{ Summary of main test results } \\
\hline & & Start & End & \\
\hline 1 & Safety equipment inspection & & & \\
\hline 2 & Pressure resistance test & & & \\
\hline 3 & Over-heating protection test & & & \\
\hline 4 & Electrical safety test & & & \\
\hline 5 & Exposure test & & & \\
\hline 6 & External thermal shock test & & & \\
\hline 7 & Rain penetration test & & & \\
\hline 8 & Internal thermal shock test & & & \\
\hline 9 & Anti-backflow inspection & & & \\
\hline 10 & Freeze resistance test & & & \\
\hline 11 & Impact resistance test & & & \\
\hline 12 & Support strength \& stiffness test & & & \\
\hline 13 & Negative pressure resistance test & & & \\
\hline 14 & Pulse pressure resistance test & & & \\
\hline
\end{tabular}

Remarks:

\section{A.4 Safety equipment inspection}

\section{A.4.1 General}

After the safety equipment inspection specified in 5.1.2, the solar water heating system and its documents shall be verified for suitability.

\section{A.4.2 Inspection items:}

a) Safety relief valves;

b) Connecting pipes between the safety relief valve and the expansion vessel;

c) Emptying pipelines.

\section{A.4.3 Inspection results:}

Give details of equipment missing and any unsuitability. 


\section{A.5 Pressure resistance test}

\section{A.5.1 General}

After the pressure resistance test specified in 5.2.4, the solar water heating system shall be inspected for damage.

\section{A.5.2 Test conditions:}

Average ambient temperature: .$^{\circ} \mathrm{C}$

Test pressure: $\mathrm{Pa}$

\section{A.5.3 Test results:}

Give details of leakage, breakage, distortion or deformation and any other failures.

\section{A.6 Over-heating protection test}

\section{A.6.1 General}

After the over-heating protection test specified in 5.3.3, the solar water heating system shall be inspected for damage.

\section{A.6.2 Test conditions:}

Average ambient temperature: ${ }^{\circ} \mathrm{C}$

Daily solar irradiation: $\mathrm{MJ} / \mathrm{m}^{2}$

Test duration: days

\section{A.6.3 Test results:}

Give details of leakage, swelling and any other failures.

\section{A.7 Electrical safety test}

\section{A.7.1 General}

After the electricity safety test specified in 5.4 .2 or 5.4 .3 , the solar water heating system shall be verified for safety.

\section{A.7.2 Test products:}

a) Air-source heat-pump assisted solar system;

b) Solar system with auxiliary electric energy. 


\section{A.7.3 Test results:}

Give details of any un-safety.

\section{A.8 Exposure test}

\section{A.8.1 General}

After the exposure test specified in 5.5.4, the solar water heating system shall be inspected for damage.

\section{A.8.2 Test conditions:}

Average ambient temperature: ${ }^{\circ} \mathrm{C}$

Daily solar irradiation: $. \mathrm{MJ} / \mathrm{m}^{2}$

Test duration: days

\section{A.8.3 Test results:}

Test results are given in Table A.2.

Table A.2 - Exposure test results

\begin{tabular}{|c|c|c|c|}
\hline Day & Time (h) & Solar irradiation $\left(\mathrm{MJ} / \mathrm{m}^{2}\right)$ & Ambient temperature $\left({ }^{\circ} \mathrm{C}\right)$ \\
\hline \multirow[t]{10}{*}{ First } & 1 & & \\
\hline & 2 & & \\
\hline & 3 & & \\
\hline & 4 & & \\
\hline & 5 & & \\
\hline & 6 & & \\
\hline & 7 & & \\
\hline & 8 & & \\
\hline & 9 & & \\
\hline & 10 & & \\
\hline \multirow[t]{10}{*}{ Second } & 1 & & \\
\hline & 2 & & \\
\hline & 3 & & \\
\hline & 4 & & \\
\hline & 5 & & \\
\hline & 6 & & \\
\hline & 7 & & \\
\hline & 8 & & \\
\hline & 9 & & \\
\hline & 10 & & \\
\hline
\end{tabular}


Give details of crack, deformation and any other failures:

\section{A.9 External thermal shock test}

\section{A.9.1 General}

After the external thermal shock test specified in 5.6.4, the solar water heating system shall be inspected for damage.

\section{A.9.2 Test conditions:}

Average ambient temperature: ${ }^{\circ} \mathrm{C}$

Daily solar irradiation: $\mathrm{MJ} / \mathrm{m}^{2}$

Average solar irradiance: $\mathrm{W} / \mathrm{m}^{2}$

Period prior to water spray: .........................h

Spray water temperature: $\ldots \ldots \ldots \ldots \ldots \ldots \ldots \ldots \ldots{ }^{\circ} \mathrm{C}$

Spray water flow-rate: ............................ L $/ \mathrm{h} \cdot \mathrm{m}^{2}$

Duration of water spray: .............................min

Absorber temperature prior to water spray: .......... ${ }^{\circ} \mathrm{C}$

Test combined with exposure test: $\quad$ Yes $\square$ No

\section{A.9.3 Test results:}

Test results are given in Table A.3.

Table A.3 - External thermal shock test results

\begin{tabular}{|c|c|c|c|}
\hline Thermal shock & Time (min) & Solar irradiance $\left(\mathrm{W} / \mathrm{m}^{2}\right)$ & Ambient temperature $\left({ }^{\circ} \mathrm{C}\right)$ \\
\hline \multirow[t]{13}{*}{ First time } & 0 & & \\
\hline & 5 & & \\
\hline & 10 & & \\
\hline & 15 & & \\
\hline & 20 & & \\
\hline & 25 & & \\
\hline & 30 & & \\
\hline & 35 & & \\
\hline & 40 & & \\
\hline & 45 & & \\
\hline & 50 & & \\
\hline & 55 & & \\
\hline & 60 & & \\
\hline
\end{tabular}




\begin{tabular}{|l|l|l|l|}
\hline \multicolumn{1}{|l|}{} & 65 & & \\
\hline & 70 & & \\
\hline & 75 & & \\
\hline & 80 & & \\
\hline & 85 & & \\
\hline & 90 & & \\
\hline Second time & 0 & & \\
\hline & 5 & & \\
\hline & 10 & & \\
\hline & 15 & & \\
\hline & 20 & & \\
\hline & 25 & & \\
\hline & 30 & & \\
\hline & 35 & & \\
\hline & 40 & & \\
\hline & 45 & & \\
\hline & 50 & & \\
\hline 55 & & & \\
\hline & 60 & & \\
\hline & 65 & & \\
\hline 70 & & \\
\hline & 75 & & \\
\hline & 80 & & \\
\hline & 85 & & \\
\hline & 90 & & \\
\hline
\end{tabular}

Give details of cracking, deformation, condensation, water penetration or loss of vacuum.

\section{A.10 Rain penetration test}

\section{A.10.1 General}

After the rain penetration test specified in 5.7.4, the solar water heating system shall be inspected for damage.

\section{A.10.2 Test conditions:}

Average ambient temperature: ${ }^{\circ} \mathrm{C}$

Average spray water temperature: .${ }^{\circ} \mathrm{C}$

Average spray water flow-rate: $\mathrm{L} / \mathrm{h} \cdot \mathrm{m}^{2}$ 
Duration of water spray: $\min$

\section{A.10.3 Test results:}

Test results are given in Table A.4.

Table A.4 - Rain penetration test results

\begin{tabular}{|l|l|l|}
\hline \multicolumn{1}{|c|}{ Time (min) } & Spray water temperature $\left(^{\circ} \mathbf{C}\right)$ & Spray water flow-rate (L/h. $\left.\mathbf{m}^{2}\right)$ \\
\hline 0 & & \\
\hline 5 & & \\
\hline 10 & & \\
\hline 15 & & \\
\hline 20 & & \\
\hline 25 & & \\
\hline 30 & & \\
\hline 35 & & \\
\hline 40 & & \\
\hline 45 & & \\
\hline 50 & & \\
\hline 55 & & \\
\hline 60 & & \\
\hline
\end{tabular}

Give details of the existence of water penetration inside the collectors.

\section{A.11 Internal thermal shock test}

\section{A.11.1 General}

After the internal thermal shock test specified in 5.8.4, the solar water heating system shall be inspected for damage.

\section{A.11.2 Test conditions:}

Average ambient temperature: $\ldots \ldots \ldots \ldots \ldots \ldots \ldots \ldots \ldots{ }^{\circ} \mathrm{C}$

Daily solar irradiation: ..................................

Average solar irradiance: .................................

Period prior to water cooling: ............................h

Temperature of cooling water/heat transfer fluid: ........... ${ }^{\circ} \mathrm{C}$

Flow-rate of cooling water/heat transfer fluid: ..............L/h.m ${ }^{2}$

Duration of water/heat transfer fluid cooling: .................min

Absorber temperature prior to water cooling: ............... ${ }^{\circ} \mathrm{C}$ 


\section{A.11.3 Test results:}

Give details of any cracking, deformation or damage.

\section{A.12 Anti-backflow inspection}

\section{A.12.1 General}

After anti-backflow inspection specified in 5.9.2, the solar water heating system shall be inspected for the possibility of backflow.

\section{A.12.2 Inspection item}

For the system with thermo-siphon circulation, visual inspection shall be performed to determine whether the lowest position of the storage tank is above the collector.

\section{A.12.3 Inspection results:}

Give details of the possibility of backflow.

\section{A.13 Freeze resistance test}

\section{A.13.1 General}

After the freeze resistance test specified in 5.10.4, the solar water heating system shall be inspected for freezing.

\section{A.13.2 Test conditions}

Average ambient temperature: $\ldots \ldots \ldots \ldots \ldots \ldots \ldots \ldots \ldots \ldots \ldots \ldots \ldots \ldots \ldots \ldots \ldots \ldots \ldots$

Freeze chamber temperature during the freezing stage: $\ldots \ldots \ldots \ldots . .{ }^{\circ} \mathrm{C}$

Freeze chamber temperature during the thawing stage: $\ldots \ldots \ldots \ldots \ldots{ }^{\circ} \mathrm{C}$

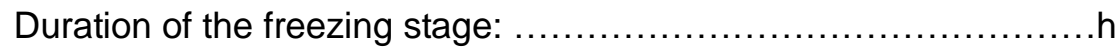

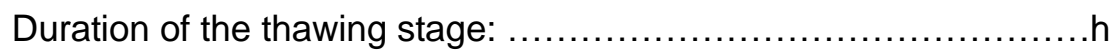

Initial water temperature in the storage tank: .................... ${ }^{\circ} \mathrm{C}$

Freezing point of the anti-freezing fluid: .......................... ${ }^{\circ} \mathrm{C}$

\section{A.13.3 Test results:}

Give details of freezing, leakage, breakage, deformation and damage. 


\section{A.14 Impact resistance test}

\section{A.14.1 General}

After the impact resistance test specified in 5.11 .2 or 5.11 .3 , the solar water heating system shall be inspected for damage.

\section{A.14.2 Test conditions}

Diameter of steel ball: $\mathrm{mm}$

Mass of steel ball: $\mathrm{kg}$

Maximum dropping height: m

\section{A.14.3 Test results:}

Give details of any damage together with appropriate photographs.

\section{A.15 Support strength \& stiffness test}

\section{A.15.1 General}

After the support strength \& stiffness test specified in 5.12.3, the support of solar water heating system shall be inspected for damage.

\section{A.15.2 Test conditions}

Off-ground height of one end when not filled with water: $\mathrm{mm}$

Off-ground duration of one end when not filled with water: $\min$

Testing load when filled with water: $\mathrm{kg}$

Testing duration when filled with water: $\min$

\section{A.15.3 Test results:}

Test results are given in Table A.5.

Table A.5 - Support strength \& stiffness test results

\begin{tabular}{|l|l|l|l|}
\hline No. of ends & Off-ground height $(\mathbf{m m})$ & Off-ground duration (min) & Support check result \\
\hline 1 & & & \\
\hline 2 & & & \\
\hline 3 & & & \\
\hline 4 & & & \\
\hline
\end{tabular}

Give details of any damage or obvious deformation. 


\section{A.16 Negative pressure resistance test}

\section{A.16.1 General}

After the negative pressure resistance test specified in 5.13.3, the solar water heating system shall be inspected for damage.

\section{A.16.2 Test conditions}

Vacuum of test device: $\mathrm{MPa}$

Testing duration: $\min$

\section{A.16.3 Test results:}

Give details of any leakage or obvious deformation.

\section{A.17 Pulse pressure resistance test}

\section{A.17.1 General}

After the pulse pressure resistance test specified in 5.14.3, the solar water heating system shall be inspected for damage.

\section{A.17.2 Test conditions}

Rated pressure: $\mathrm{MPa}$

Pulse pressure: MPa to $\mathrm{MPa}$

Pulse frequency: times /min

Pulse cycles: times

Duration of maintaining the rated pressure: $\min$

\section{A.17.3 Test results:}

Test results are given in Table A.6.

Table A.6 - Pulse pressure resistance test results

\begin{tabular}{|l|l|l|l|}
\hline Cycle Times & Rated pressure (MPa) & Maintaining duration (min) & Container check result \\
\hline 10,000 & & & \\
\hline 20,000 & & & \\
\hline 30,000 & & & \\
\hline 40,000 & & & \\
\hline 50,000 & & & \\
\hline 60,000 & & & \\
\hline 70,000 & & & \\
\hline 80,000 & & & \\
\hline
\end{tabular}


Give details of any leakage or obvious deformation. 


\section{Bibliography}

[1] Chinese National Standard, GB/T 19141-2011, Specifications of domestic solar water heating systems. 